\title{
Suicidal plan, attempt, and associated factors among patients with diabetes in Felegehiwot referral hospital, Bahirdar, Ethiopia: cross-sectional study
}

\author{
Mogesie Necho ${ }^{1 *}$, Solomon Mekonnen ${ }^{2}$, Kelemua Haile $^{3}$, Mengesha Birkie $^{4}$ and Asmare Belete ${ }^{4}$
}

\begin{abstract}
Background: Diabetes is a highly prevalent non-communicable disease which is prone to more psychiatric complications like suicide; however, research into this area is limited. Assessing suicidal plan and attempt as well as its determinants are therefore important.

Method: Institution based cross-sectional study was conducted from May 21 to June 21 at the diabetic outpatient clinic by recruiting 421 participants using systematic sampling. Suicide manual of the composite international diagnostic interview (CIDI) was used to assess suicidal plan and attempt. Chart review was used to obtain data regarding the co-morbidity of medical illness and complications of diabetes mellitus. Binary logistic regression was used to identify factors associated with suicidal attempt. Odds ratio with $95 \% \mathrm{Cl}$ was employed and variables with a $p$-value of $<0.05$ in multivariable logistic regression were declared significant.

Results: From 423 participants 421 participated in the study with $99.5 \%$ response rate. The mean age $( \pm$ SD) of the respondents was 38.0( $( \pm 13.9)$ years. The lifetime prevalence of Suicidal plan; an attempt was found to be 10.7 and $7.6 \%$ respectively. Being female ( $\mathrm{AOR}=2.14,95 \% \mathrm{Cl}: 1.10,5.65)$, poor social support ( $\mathrm{AOR}=3.21,95 \% \mathrm{Cl}: 1.26,8.98)$, comorbid depression ( $\mathrm{AOR}=6.40,95 \% \mathrm{Cl}: 2.56,15.46)$ and poor glycemic control $(\mathrm{AOR}=4.38,95 \% \mathrm{Cl}: 1.66,9.59)$ were factors associated with lifetime suicidal attempt.

Conclusion: The prevalence of suicidal attempt among Diabetes patients is high (7.6\%). The suicidal attempt had a statistically significant association with female gender, comorbidity with depression, poor social support and poor glycemic control. Therefore the result of this study helps to do early screening, treatment, and referral of patients with suicidal attempt.
\end{abstract}

Keywords: Suicidal behavior, Diabetes mellitus, Sub-Saharan Africa, Ethiopia

\section{Background}

Suicide is defined as intentional self-inflicted death and a suicidal attempt is an intentional but unsuccessful act of killing self which are both major public health priorities [1-3]. Existing literature reports that the history of a prior suicide attempt is a statistically significant risk factor associated with future self-destructive including death by suicide $[4,5]$. A suicide attempt should have the following

\footnotetext{
* Correspondence: nechomoges2014@gmail.com

${ }^{1}$ Department of Psychiatry, Wollo University, College of Medicine and Health Sciences, Dessie, Ethiopia

Full list of author information is available at the end of the article
}

possessions; self-initiated, potentially self-injurious behavior, presence of intent to die and nonfatal outcome [6]. Other non-fatal suicidal behaviors include deliberate selfharm (DSH), non-suicidal self-injury (NSSI), suicidal threats and suicidal gestures [6].

Globally, suicide represents $1.8 \%$ of the burden of disease and estimates suggest that this will rise to $2.4 \%$ in 2020 [7]. According to World Health Organization (WHO), suicide accounts for $50 \%$ of all violent deaths in men and $71 \%$ in women and is the 2 nd leading cause of death in 15-29-year age group worldwide [8]. Nearly $85 \%$ of the suicides in the world occur in low and

(c) The Author(s). 2019 Open Access This article is distributed under the terms of the Creative Commons Attribution 4.0 International License (http://creativecommons.org/licenses/by/4.0/), which permits unrestricted use, distribution, and 
middle-income countries (LMICS), of this;34,000 occur in Africa per year [9]. In Ethiopia, suicidal behavior affects about $6.3 \%$ of the population [10]. Suicidal attempt among people with DM had been reported as high as $58.5 \%$ [11] in the USA which is higher than the prevalence in the general population (1.1 to $4.6 \%$ ).

Suicidal behaviors in DM was significantly associated with lower than high school education and female gender in USA [12], alcohol use and cigarette smoking in USA [13], depression in USA [13], South Korea [14], Brazil [15], duration of illness longer than 5 years and medication non adherence in two USA studies $[11,16]$.

The impacts of suicide are not only loss of life, but the mental, physical and emotional stress imposed on family members and costs to resources, as people with attempted suicide often require help from health care and psychiatric institutes [6]. Prior suicide attempts are one of the strongest predictors of completed suicide [17, 18], suggesting that suicidal behaviors like ideation, plans and attempts as useful outcomes to study.

However, research into this area is limited. So this study aimed to assess the prevalence and determining factors of the suicidal plan and attempt among patients with diabetes mellitus at Felegehiwot referral hospital, Bahirdar, Northwest Ethiopia, 2017.

\section{Materials and methods}

\section{Study design and period}

An institution-based cross-sectional study was conducted from May 21 to June 21, 2017.

\section{Study setting and population}

This study was conducted at a diabetic clinic at Felegehiwot Referral Hospital. It is located in Bahir Dar; the capital city of Amhara region. It has a catchment population of more than 5.5 million people [19]. Currently, Felegehiwot referral hospital serves the population in the region and is open $24 \mathrm{~h}$ for emergency service. In Felegehiwot Referral Hospital, there are different departments, units, and clinics that provide specialized service. These include a mental health clinic, ophthalmology, internal medicine, outpatient diabetic follow up clinic, dermatology, pediatrics, gynecology/obstetrics, surgery, dentistry and physiotherapy department, hospital pharmacy; intensive care unit, operation room unit, anti-retroviral therapy, and tuberculosis clinic.

The outpatient follow-up department is open in normal working hours five days weekly from Monday to Friday. There are more than 1984 diabetic patients registered for follow-up previously in the clinic. In general, the clinic gives service for around 1384 patients per month and nearly 346 patients attend the clinic weekly [20].

\section{Inclusion criteria}

Diabetic Mellitus patients18 years and older on follow up visit for DM at the diabetic outpatient clinic of Felegehiwot referral hospital during the data collection period were included.

\section{Exclusion criteria}

Patients who were seriously ill and in difficulty of communication during the data collection period were excluded.

\section{Sample size determination and sampling technique}

The sample size for the study was calculated using single population proportion formula, considering an estimated prevalence of $50 \%$ since there is no previous published study on the prevalence of suicidal attempt in DM patients in Ethiopia, 5\% margin of error, 95\% confidence level and 10\% non-response rate. The sample size was calculated to be 423 . The sampling interval $(K=3)$ was determined by dividing the expected number of diabetic patients with follow up per month into the sample size (1384/423). The first patient was selected from the first three by a lottery method then every third of respondents included in the study.

\section{Operational definitions}

Suicidal attempt: is defined as if the respondent answers for the question have you ever attempted suicide? If the answer is yes, the respondent has a suicidal attempt [21].

Depression: Score $\geq 5$ on patient health questionnaire9 depression screening scale [22].

Adherence to medication: low-adherence if a score is $<6$, medium adherence if a score is 6 and 7 , and high adherence if a score is 8 on 8-Item Morisky medication adherence scale [23-26].

Comorbid medical illness: the presence of other diagnosed medical disorder with diabetes mellitus. Social support: individuals who scored $\geq 9$ (moderate and strong) on the Oslo 3-item social support scale [27]. Glycemic control: Glycemic control was assessed using a fasting blood glucose level of the previous visit from the medical chart of patients. Reading $\leq 130 \mathrm{mg} / \mathrm{dl}$ was considered as good control and FBG level $>130$ $\mathrm{mg} / \mathrm{dl}$ was considered as a poor control [28].

Current substance use: use of at least one of the specified substance within the last 3 months [29]. Moderate physical activity: was defined as routine walking at least five times per week for at least $30 \mathrm{~min}$ at a time or engaging during the survey period in regular moderate (at least five times per week for at least $30 \mathrm{~min}$ at a time) by the American College of Sports Medicine Guidelines [30]. 
Monthly income: Average monthly income was categorized as $<\$ 27, \$ 27-\$ 43.56$ and $\geq \$ 43.56$.

\section{Data collection}

The pre-test was done 1 week before the data collection period among 21 (5\%) of sample size at Adisalem Hospital. Data was collected by BSc nurses after training was given. The suicide manual of WHO composite international diagnostic interview (CIDI) was used to assess suicidal attempt among patients with diabetes mellitus. Depression was assessed using Patient Health Questionnaire-9 which has been validated in the general hospital setting in Ethiopia with sensitivity $86 \%$ and specificity $67 \%$ for diagnosing MDD among Ethiopian adults [22].

Medication adherence was assessed using Morisky- 8 item medication adherence scale. MMAS- 8 is the latest medication adherence assessment scales and has a good specificity of $53 \%$ and sensitivity of $93 \%$ [31, 32]. Social support was assessed with Oslo-3-item social support scale [27].

\section{Data processing and analysis}

Data was entered using Epi-info version 7, exported and analyzed using the Statistical Packages for Social Sciences, version 20. Descriptive statistics measures like frequency, mean, median, standard deviation and crosstabs were used to summarize the outcome and predictor variables. A logistic regression model was fitted to asses potential risk factors for a suicidal attempt. Variables with $p$-value $<0.25$ in bivariate analysis were fitted into a multivariable logistic regression to control the effect of confounders. Odds ratio with $95 \% \mathrm{CI}$ was employed and statistical significance were declared with a p-value of $<$ 0.05 in multivariable logistic regression.

\section{Results}

Socio-demographic characteristics of the participants

A total of 421 respondents were included in the study with a response rate of $99.5 \%$. The mean age $( \pm \mathrm{SD})$ of the respondents was $38.0(( \pm 13.9)$ year. Among respondents $227(53.9 \%), \quad 353(83.6 \%), \quad 256(60.8 \%), \quad 192(45.6 \%)$ and $196(46.6 \%)$ were males, orthodox, married, not educated and farmers respectively (Table 1$)$.

\section{Clinical characteristics of the respondents}

Three hundred sixty-three (86\%) and 56 (14\%) of respondents were found to have type-II and type-I DM respectively. Regarding their diabetes medication; 184(43.7\%) were on insulin. More than half of study participants; $257(61 \%)$ had been living with diabetes for $<5$ years. Fiftysix (13.3\%) of participants had a comorbid medical illness of which hypertension was the commonest one, $44(78.6 \%)$. The prevalence of comorbid depression in the study was found to be $38.7 \%$ (Table 2).
Table 1 Descriptions of Socio demographic characteristics among patients with diabetes mellitus on follow up at Felegehiwot referral hospital $(n=421)$, Bahirdar, Ethiopia, 2017

\begin{tabular}{|c|c|c|}
\hline Variable & Frequency & Percentage \\
\hline \multicolumn{3}{|l|}{ Age group } \\
\hline $18-24$ & 74 & 17.6 \\
\hline $25-34$ & 116 & 27.6 \\
\hline $35-44$ & 97 & 23 \\
\hline $45-54$ & 77 & 18.3 \\
\hline$\geq 55$ & 57 & 13.5 \\
\hline \multicolumn{3}{|l|}{ Sex } \\
\hline Male & 227 & 53.9 \\
\hline Female & 194 & 46.1 \\
\hline \multicolumn{3}{|l|}{ Marital status } \\
\hline Married & 256 & 60.8 \\
\hline Single & 93 & 22.5 \\
\hline Widowed/divorced & 72 & 16.7 \\
\hline \multicolumn{3}{|l|}{ Religion } \\
\hline Orthodox & 352 & 83.6 \\
\hline Muslim & 51 & 12.1 \\
\hline Protestant & 18 & 4.3 \\
\hline \multicolumn{3}{|l|}{ Occupation } \\
\hline Government employee & 71 & 16.9 \\
\hline Private employee & 58 & 13.8 \\
\hline Unemployed & 28 & 6.7 \\
\hline Farmer & 196 & 46.6 \\
\hline Student & 26 & 6.2 \\
\hline Others & 42 & 10 \\
\hline \multicolumn{3}{|l|}{ Educational status } \\
\hline No formal education & 192 & 45.6 \\
\hline Grade 1-8 & 93 & 22.1 \\
\hline Grade9-12 & 58 & 13.8 \\
\hline Diploma and above & 78 & 18.5 \\
\hline \multicolumn{3}{|l|}{ Monthly income } \\
\hline$<\$ 27$ & 159 & 37.8 \\
\hline$\$ 27-\$ 43.56$ & 96 & 22.8 \\
\hline$>\$ 43.56$ & 166 & 39.4 \\
\hline \multicolumn{3}{|l|}{ With whom patient is living } \\
\hline With family & 375 & 89 \\
\hline Alone & 46 & 11 \\
\hline \multicolumn{3}{|l|}{ Social support } \\
\hline Poor & 242 & 57.5 \\
\hline Moderate & 128 & 30.4 \\
\hline Strong & 51 & 12.1 \\
\hline
\end{tabular}


Table 2 Clinical characteristics of diabetic patients attending Felegehiwot referral Hospital, Diabetic Clinic $(n=421)$, Bahirdar, Northwest Ethiopia, July 2017

\begin{tabular}{|c|c|c|}
\hline Variable & Frequency & Percentage \\
\hline \multicolumn{3}{|l|}{ Type of DM } \\
\hline Type1 & 58 & 13.8 \\
\hline Type 2 & 363 & 86.2 \\
\hline \multicolumn{3}{|l|}{ Duration since DM dx } \\
\hline$<5$ years & 257 & 61 \\
\hline$>=5$ years & 164 & 39 \\
\hline \multicolumn{3}{|l|}{ Current DM treatment } \\
\hline Insulin & 184 & 43.7 \\
\hline Insulin and oral agents & 57 & 13.6 \\
\hline Oral hypoglycemic agents & 180 & 42.8 \\
\hline \multicolumn{3}{|l|}{ Comorbid medical illness } \\
\hline HTN & 44 & 10.5 \\
\hline HIV & 6 & 1.5 \\
\hline Asthma & 3 & 0.65 \\
\hline Renal diseases & 3 & 0.65 \\
\hline No medical illness & 365 & 86.7 \\
\hline \multicolumn{3}{|l|}{ Complication due to DM } \\
\hline Yes & 18 & 4.3 \\
\hline No & 401 & 95.2 \\
\hline \multicolumn{3}{|l|}{ Glycemic control } \\
\hline Poor & 205 & 48.7 \\
\hline Good & 216 & 51.3 \\
\hline \multicolumn{3}{|l|}{ Medication adherence } \\
\hline low & 85 & 20.2 \\
\hline Medium & 167 & 39.7 \\
\hline High & 169 & 40.1 \\
\hline \multicolumn{3}{|l|}{ Moderate physical activity } \\
\hline Yes & 129 & 30.6 \\
\hline No & 292 & 69.4 \\
\hline \multicolumn{3}{|l|}{ Co morbid depression } \\
\hline Yes & 163 & 38.7 \\
\hline No & 258 & 61.3 \\
\hline \multicolumn{3}{|l|}{ Body mass index(kg/m2) } \\
\hline$<18.5$ & 40 & 9.5 \\
\hline $18.5-24.9$ & 333 & 79.1 \\
\hline$\geq 25.00$ & 48 & 11.4 \\
\hline \multicolumn{3}{|c|}{ Family history of suicidal attempt } \\
\hline Yes & 15 & 3.6 \\
\hline No & 406 & 96.4 \\
\hline
\end{tabular}

\section{Substance use characteristics of respondents}

One hundred thirty-six (32.3\%) of the respondents had a history of substance use within the past three months before data collection time. Among these; the majority, 123(90.5\%) reported that they were using alcohol and $11(8 \%)$ of them were smoking a cigarette, but only two of the respondents $(1.5 \%)$ had used chat within the past three months (Table 3).

\section{Prevalence of suicidal attempt among patients with diabetes mellitus}

The lifetime prevalence of suicidal attempt in the study participants was $32(7.6 \%)$ and $12(36.4 \%)$ of them had reported attempt history within 12 months before the data collection time. Of those who attempted suicide $28(87.5 \%)$ had a plan and 21(65.6\%) were females. Considering types of DM, it was found that suicidal attempt is $8(14 \%)$ in type 1 and $24(6.6 \%)$ in type $2 \mathrm{DM}$ respectively (Table 4). Regarding the frequency of attempt, 25(78.1\%), 5(15.6\%) and 2(6.3\%) of participants had attempted suicide once, twice and more than two times

Table 3 Substance use characteristics of study participants at Felegehiwot Referral Hospital,Bahir Dar, Northwest Ethiopia, 2017 $(n=421)$

\begin{tabular}{|c|c|c|}
\hline Variables & Frequency & Percentages \\
\hline \multicolumn{3}{|c|}{ Lifetime substance use } \\
\hline Yes & 209 & 49.6 \\
\hline No & 212 & 50.4 \\
\hline \multicolumn{3}{|c|}{ Lifetime alcohol use } \\
\hline Yes & 193 & 45.8 \\
\hline No & 228 & 54.2 \\
\hline \multicolumn{3}{|c|}{ Lifetime cigarette smoking } \\
\hline Yes & 12 & 2.85 \\
\hline No & 409 & 97.15 \\
\hline \multicolumn{3}{|c|}{ Lifetime chat chewing } \\
\hline Yes & 3 & 7.1 \\
\hline No & 418 & 92.9 \\
\hline \multicolumn{3}{|c|}{ Current substance use } \\
\hline Yes & 136 & 32.3 \\
\hline No & 285 & 67.7 \\
\hline \multicolumn{3}{|c|}{ Current alcohol use } \\
\hline Yes & 123 & 29.2 \\
\hline No & 298 & 70.8 \\
\hline \multicolumn{3}{|c|}{ Current cigarette smoking } \\
\hline Yes & 11 & 2.6 \\
\hline No & 410 & 97.4 \\
\hline \multicolumn{3}{|c|}{ Current chat chewing } \\
\hline Yes & 2 & 0.5 \\
\hline No & 419 & 99.5 \\
\hline
\end{tabular}


Table 4 Frequency distribution of suicidal attempt among diabetes mellitus patients at outpatient department of Felegehiwot Referral Hospital, Bahirdar, Ethiopia,2017( $\mathrm{n}=421$ )

\begin{tabular}{|c|c|c|}
\hline Variable & Frequency & Percentage \\
\hline \multicolumn{3}{|l|}{ Lifetime suicidal ideation } \\
\hline Yes & 83 & 19.7 \\
\hline No & 338 & 80.3 \\
\hline \multicolumn{3}{|c|}{ Lifetime suicidal ideation } \\
\hline Type 1 DM & 21 & 25.3 \\
\hline Type 2 DM & 62 & 74.7 \\
\hline \multicolumn{3}{|c|}{ Duration of suicidal ideation } \\
\hline$\leq 12$ months & 28 & 33.7 \\
\hline$>12$ months & 55 & 66.3 \\
\hline \multicolumn{3}{|c|}{ Suicidal ideation 1 month } \\
\hline Yes & 7 & 1.7 \\
\hline No & 417 & 98.3 \\
\hline \multicolumn{3}{|l|}{ Lifetime plan of suicide } \\
\hline Yes & 45 & 10.7 \\
\hline No & 376 & 89.3 \\
\hline \multicolumn{3}{|l|}{ Lifetime suicidal attempt } \\
\hline Yes & 32 & 7.6 \\
\hline No & 389 & 92.4 \\
\hline \multicolumn{3}{|l|}{ Lifetime suicidal attempt } \\
\hline Type1 DM & 8 & 25 \\
\hline Type 2 DM & 24 & 75 \\
\hline \multicolumn{3}{|c|}{ Duration of suicidal attempt } \\
\hline$\leq 12$ months & 12 & 36.4 \\
\hline$>12$ months & 20 & 63.6 \\
\hline \multicolumn{3}{|c|}{ Reasons for suicidal attempt } \\
\hline Family conflict & 6 & 18.75 \\
\hline Economic problem & 6 & 18.75 \\
\hline Death in family & 2 & 6.25 \\
\hline Related to DM & 12 & 37.5 \\
\hline Others & 6 & 18.75 \\
\hline
\end{tabular}

respectively in their lifetime (Fig. 1). The most commonly used method for the suicidal attempt was hanging 15(46.8\%) followed by poisoning 13(40.6\%) (Fig. 2). Among participants who attempted suicide, 18(56\%) made a serious attempt to kill themselves, 5(15.6\%) tried to kill themselves but knew that method used was not fool-proof suggests that in both of the above cases the participants had a real intent to die. The rest $9(28 \%)$ of attempters reported that their attempt was a shout for help but no real intent to die (Table 4).

\section{Factors associated with lifetime suicidal attempt among people with diabetes mellitus}

The result of this study shows that being female was about 2.14 times $(\mathrm{AOR}=2.14,95 \% \mathrm{CI}: 1.10,5.65)$ more likely to attempt suicide when compared to male. The odds of attempting suicide among participants with poor social support was 3.21 times higher as compared to participants with good social support $(\mathrm{AOR}=3.21,95 \% \mathrm{CI}: 1.26,8.98)$.

The presence of comorbid depression was significantly associated with a suicidal attempt in the current study. Participants with comorbid depression were 6.4 times more likely to attempt suicide as compared to those who do not have comorbid depression $\mathrm{AOR}=6.40,95 \% \mathrm{CI}$ $2.56,15.46)$. The odds of having suicidal attempt among participants with poor glycemic control was 4.4 times higher than participants with good control of their blood glucose level as measured by their fasting blood sugar test $(\mathrm{AOR}=4.38,95 \% \mathrm{CI}: 1.66,9.59)$ (Table 5).

\section{Discussion}

So far this study was conducted on one of the least investigated mental health problem among people with diabetes mellitus in Ethiopia. The lifetime prevalence of suicidal attempt was $7.6 \%$ (95\%CI: $5.20,10.50)$.

The prevalence of lifetime suicidal attempt in this study was in line with studies conducted at USA $10 \%$ [15] and 6.4\% [11]. On the other hand, it was higher than the result from studies in South Carolina 4\% [16]

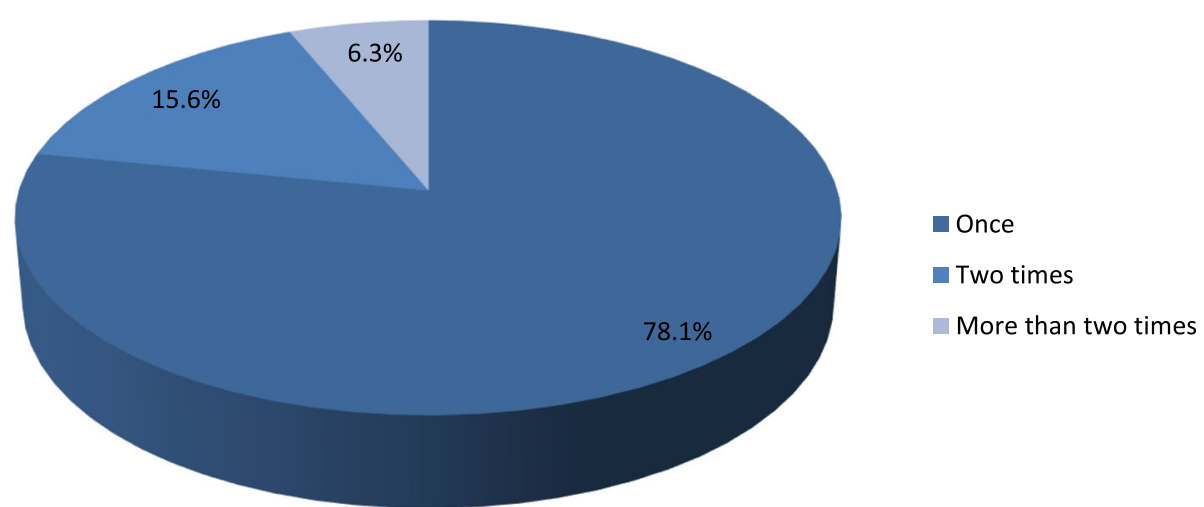

Fig. 1 Percentage distribution of suicidal attempt among patients with diabetes mellitus at Felegehiwot Referral Hospital, Bahirdar, Ethiopia, 2017 


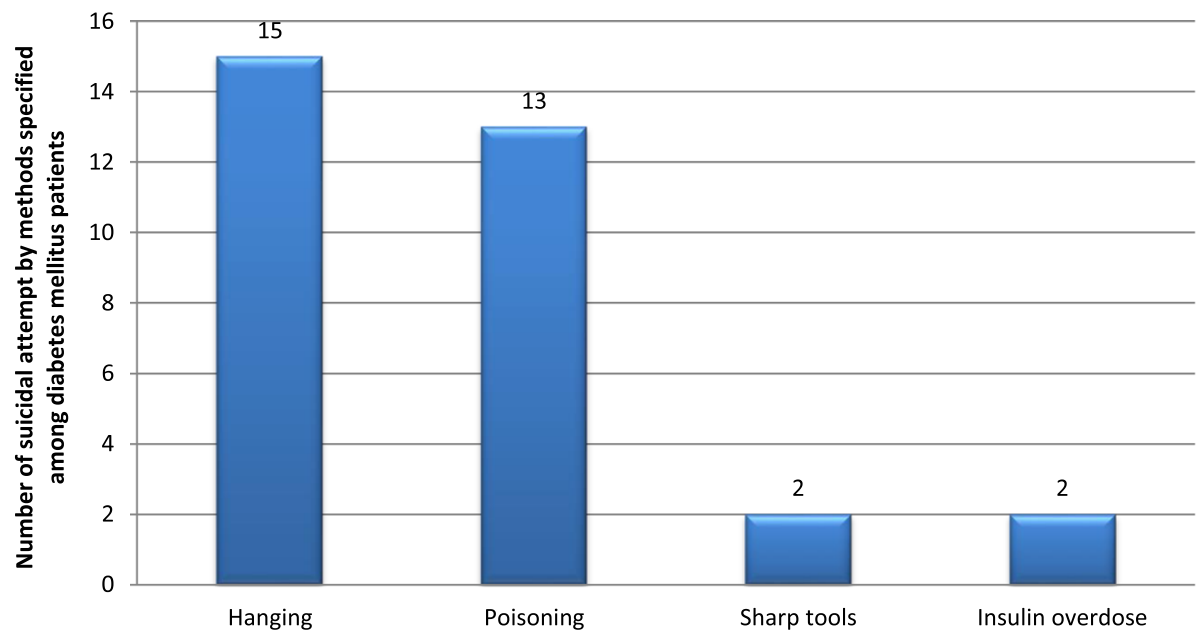

Fig. 2 A graph showing percentage distribution of methods of suicidal attempt among diabetes mellitus patients attending outpatient follow up department of Felegehiwot referral hospital, Bahirdar, Ethiopia, 2017

and Korea $1.3 \%$ [33]. On the contrary; the result was lower than findings from Newjersy13.5\% [13]. This might be due to the socio-cultural difference in which suicidal behaviors are stigmatized in our society and religiously condemned and so patients may under-report suicidal attempt $[10,34]$. It might also be due to a difference in study subjects including both type1 and 2 DM in current but only type 1 in new jersey and South Carolina studies. Besides, it was a case-control design in Newjersy [13] and a national survey in Korea [33].

The most commonly used method for a suicidal attempt in patients with diabetes mellitus in this study is hanging 15 (46.9\%). This is consistent with the method of suicide attempt known to be commonest globally [1] but different from findings in other studies. For instance, a study in northern Finland shows that self-poisoning was the commonest method 48\% [35] and another study in the USA found that diabetes-related methods like insulin overdose are most common [11]. The difference might be due to accessibility to opportunities of suicidal methods, knowledge of participants regarding methods of attempt and socio-cultural differences.

Regarding factors associated with suicidal attempt, the result of this study shows that being female was about 2.14 times more likely to have suicidal attempt when compared to male and this is under most literature. This finding was supported by studies conducted in the USA $[13,36]$. This might be due to cultural influences in which women may not discuss their issues openly as men so suicide attempts may be used as a means of externalizing their suppressed emotion [37].

The odds of attempting suicide among participants with poor social support was found to be 3.21 times higher as compared to participants with good social support as measured by Oslo 3 item social support scale.
This is in agreement with other studies [7, 8, 38]. This can be explained as where social support is available; alternatives of coping from suicidal attempt are more likely before a person attempts suicide.

Participants with comorbid depression were 6.4 times more likely to attempt suicide as compared to those who do not have comorbid depression. This is consistent with several studies in the USA [13, 15, 39, 40] and Korea [14]. The reason may be depression will lead to a decrease in serotonin levels and studies show an association between serotonin decrease and suicidal behavior $[6,41]$. It may also be due to the direct impact of depression on patients which makes them socially withdrawn, hopeless and worthless.

The odds of attempting suicide among participants with poor glycolic control were 2.6 times higher than those with good glycemic control. This is in agreement with studies in Brazil [42] and South Korea [43]. The possible reason is that glycemic control might be a potential clinical mediator of the relationship between suicidal attempt and diabetes complications. Studies should be conducted to confirm this proposed mediation $[43,44]$.

The following limitations need to be considered in interpreting the results of this study. First; lack of a dedicated instrument for assessing suicide risk. Second, we assessed depression using PHQ-9 and vegetative symptoms like poor appetite, fatigue, lack of sleep are common in diabetes patients which might overestimate the depression measurement. Besides, the use of the medical chart of patient's without written consent is also the limitation of this study.

\section{Conclusion}

The prevalence of suicidal attempt among diabetes mellitus patients was found to be high which indicates that 
Table 5 Bivariate and multivariable Logistic Regression analysis showing the Associations between some of the factors and life time suicidal Attempt among diabetic patients at Felegehiwot Referral hospital, Bahir Dar, Ethiopia, 2017( $n=421)$

\begin{tabular}{|c|c|c|c|c|}
\hline \multirow[t]{2}{*}{ Explanatory variable } & \multicolumn{2}{|c|}{$\begin{array}{l}\text { Suicidal } \\
\text { attempt }\end{array}$} & \multirow[t]{2}{*}{ COR(95\% Cl) } & \multirow[t]{2}{*}{$\mathrm{AOR}(95 \% \mathrm{Cl})$} \\
\hline & Yes & No & & \\
\hline \multicolumn{5}{|l|}{ Sex } \\
\hline Male & 11 & 216 & 1.00 & 1.00 \\
\hline Female & 21 & 173 & $2.38(1.12-5.08)$ & $2.14(1.10-5.65)^{a}$ \\
\hline \multicolumn{5}{|l|}{ Occupational status } \\
\hline Employed $^{a}$ & 10 & 119 & 1.00 & 1.00 \\
\hline Unemployed & 5 & 23 & $2.59(0.81-8.27)$ & $2.53(0.53-12.11)$ \\
\hline Farmer & 12 & 184 & $0.78(0.32-1.85)$ & $0.44(0.12-1.71)$ \\
\hline Student & 3 & 23 & $1.55(0.39-6.08)$ & $2.09(0.31-14.08)$ \\
\hline Others $^{a}$ & 2 & 40 & $0.59(0.12-2.83)$ & $0.21(0.02-1.84)$ \\
\hline \multicolumn{5}{|l|}{ Social support } \\
\hline Poor & 26 & 216 & $3.47(1.39-8.62)$ & $3.21(1.26-8.98)^{b}$ \\
\hline Good & 6 & 173 & 1.00 & 1.00 \\
\hline \multicolumn{5}{|l|}{ Duration of DM } \\
\hline$<5$ Years & 15 & 242 & 1.00 & 1.00 \\
\hline$\geq 5$ Years & 17 & 147 & $1.86(0.90-3.85)$ & $1.906(0.75-4.84)$ \\
\hline \multicolumn{5}{|l|}{ Glycemic control } \\
\hline Poor & 23 & 182 & $2.90(1.31-6.44)$ & $4.38(1.66-9.59)^{b}$ \\
\hline Good & 9 & 207 & 1.00 & 1.00 \\
\hline \multicolumn{5}{|l|}{ Depression } \\
\hline Yes & 22 & 141 & $3.87(1.78-8.40)$ & $6.40(2.56-15.46)^{c}$ \\
\hline No & 10 & 248 & 1.00 & 1.00 \\
\hline \multicolumn{5}{|l|}{ Educational level } \\
\hline No formal education & 9 & 183 & $0.59(0.20-1.72)$ & $0.91(0.18-4.53)$ \\
\hline Grade1-8 & 15 & 78 & $2.31(0.85-6.27)$ & $4.05(0.78-20.84)$ \\
\hline Grade9-12 & 2 & 56 & $0.43(0.08-2.20)$ & $\begin{array}{l}0.34 \\
(0.05-2.56)\end{array}$ \\
\hline Diploma and above & 6 & 72 & 1.00 & 1.00 \\
\hline
\end{tabular}

${ }^{a} p$-value $<0.05,{ }^{b} p$-value $<0.01,{ }^{c} p$-value $<0.001$

Model chi-square $=8.467, \mathrm{df}=8$ and $\mathrm{sig}=0.389$

a Employed are both Government and Private employed

${ }^{a}$ Others are merchants and housewife

diabetes mellitus is a public health concern. Comorbidity of depression, being female, poor glycemic level and poor social support was found to a have statistically significant association with suicidal attempt. So the result of this study helps to do early screening, treatment, and referral of patients with suicidal attempt.

\section{Abbreviations}

BMI: Body mass index; CIDI: Composite international diagnostic interview; DM: Diabetes mellitus; OR: Odds ratio; PHQ-9: Patient health questionnaire-9; SPSS: Statistical package for social science; UOG: University of Gondar; USA: United States of America; WHO: World health organization

\section{Acknowledgments}

We would like to express our deepest gratitude to the University of Gondar College of medicine and health science \&Felegehiwot Specialized hospital for all support provided. Furthermore, our thanks go to data collectors, supervisors and participants of this study for devoting their precious time.

\section{Authors' contributions}

MN is the principal investigator running the whole research process. SM and $\mathrm{KH}$ provides comments, suggestion and advises the conduct of research, and $\mathrm{MB}$ assisted in the design, conduct and doing analyses of the research and manuscript preparation. $A B$ contributed to the review of the manuscript. All authors read and ratified the manuscript.

\section{Funding}

This research was funded by Amanuel Mental Specialized Hospital. The funding body has no role in the design of study, collection, analysis of data and writes up of the manuscript.

\section{Availability of data and materials}

The datasets used throughout this research process are available from the corresponding author on reasonable request.

\section{Ethics approval and consent to participate}

Ethical approval was received from the Institutional Review Board of University of Gondar and ethical committee of Amanuel mental specialized hospital. Authors presented a request to take a verbal consent form study participants since involvement in the research pose no more than a minimal risk to the study subjects and the named institution above approved it. So, Participants were informed about the objectives of the study before the interview began and informed verbal consent was obtained from each participant. Patients who had current suicidal attempt were referred to a mental health clinic for further evaluation and treatment.

\section{Consent for publication}

Not Applicable.

\section{Competing interests}

The authors declare that they have no competing interests.

\section{Author details}

${ }^{1}$ Department of Psychiatry, Wollo University, College of Medicine and Health Sciences, Dessie, Ethiopia. ${ }^{2}$ Department of Public Health, University of Gondar, College of Medicine and Health Sciences, Gondar, Ethiopia.

${ }^{3}$ AmanuelMentalSpecialized Hospital, Addis Ababa, Ethiopia. ${ }^{4}$ Department of Psychiatry, Wollo University, College of Medicine and Health Sciences, Dessie, Ethiopia.

Received: 4 March 2019 Accepted: 22 August 2019

Published online: 27 August 2019

\section{References}

1. Sadock BJ, Sadock VA. Kaplan and Sadock's synopsis of psychiatry: behavioral sciences/clinical psychiatry: Lippincott Williams \& Wilkins; 2011.

2. Jacobs DG, Baldessarini RJ, Conwell Y, Fawcett JA, Horton L, Meltzer H, et al. Assessment and treatment of patients with suicidal behaviors; 2010

3. Kim M-H, Jung-Choi K, Jun H-J, Kawachi I. Socioeconomic inequalities in suicidal ideation, parasuicides, and completed suicides in South Korea. Soc Sci Med. 2010;70(8):1254-61.

4. Silverman MM, Berman AL, Sanddal ND, O'carroll PW, Joiner TE Jr. Rebuilding the tower of babel: a revised nomenclature for the study of suicide and suicidal behaviors part 2: suicide-related ideations, communications, and behaviors. Suicide Life Threat Behav. 2007;37(3):264-77.

5. Silverman MM, Berman AL, Sanddal ND, O'carroll PW, Joiner TE Jr. Rebuilding the tower of babel: a revised nomenclature for the study of suicide and suicidal behaviors part 1: background, rationale, and methodology. Suicide Life Threat Behav. 2007:37(3):248-63.

6. Apter A. Suicide and suicidal behavior. Public Health Rev. 2012;34(2):1.

7. Khan MM. Suicide prevention and developing countries. JR Soc Med. 2005; 98:459-63.

8. Organization WH. Preventing suicide: a global imperative: World Health Organization; 2014. 
9. Mars B, Burrows S, Hjelmeland H, Gunnell D. Suicidal behavior across the African continent: a review of the literature. BMC Public Health. 2014;14(1):606.

10. Fekadu A, Medhin G, Selamu M, Shiferaw T, Hailemariam M, Rathod SD, et al. Non-fatal suicidal behavior in rural Ethiopia: a cross-sectional facilityand population-based study. BMC Psychiatry. 2016;16(1):75.

11. Goldston DB, Kovacs M, Ho VY, Parrone PL, Stiffler L. Suicidal ideation and suicide attempts among youth with insulin-dependent diabetes mellitus. J Am Acad Child Adolesc Psychiatry. 1994;33(2):240-6.

12. Goodwin RD, Kroenke K, Hoven CW, Spitzer RL. Major depression, physical illness, and suicidal ideation in primary care. Psychosom Med. 2003;65(4):501-5.

13. Roy A, Roy M, Janal M. Suicide attempts and ideation in African-American type 1 diabetic patients. Psychiatry Res. 2010;179(1):53-6.

14. Han SJ, Kim HJ, Choi YJ, Lee KW, Kim DJ. Increased risk of suicidal ideation in Korean adults with both diabetes and depression. Diabetes Res Clin Pract. 2013;101(3):e14-e7.

15. Myers AK, Grannemann BD, Lingvay I, Trivedi MH. Brief report: depression and history of suicide attempts in adults with new-onset type 2 diabetes. Psychoneuroendocrinology. 2013;38(11):2810-4.

16. Goldston DB, Kelley AE, Reboussin DM, Daniel SS, Smith JA, Schwartz RP, et al. Suicidal ideation and behavior and noncompliance with the medical regimen among diabetic adolescents. J Am Acad Child Adolesc Psychiatry. 1997;36(11):1528-36.

17. Parra-Uribe I, Blasco-Fontecilla H. Risk of re-attempts and suicide death after a suicide attempt: a survival analysis. BMC Psychiatry. 2017;17(1):163.

18. Turecki G, Brent DA. Suicide and suicidal behavior. Lancet. 2016;387(10024): 1227-39 Epub 2015/09/20.

19. Belayneh M. Inpatient satisfaction and associated factors towards nursing care at Felegehiwot referral hospital, Amhara regional state, Northwest Ethiopia.

20. Wordofa MB. Prevalence of depression and associated factors among adult diabetic patients attending outpatient department, at Felege Hiwot referral hospital. Bahir Dar: AAU, 2016; 2016.

21. Kessler RC, Üstün TB. The world mental health (WMH) survey initiative version of the world health organization (WHO) composite international diagnostic interview (CIDI). Int J Methods Psychiatr Res. 2004;13(2):93-121.

22. Gelaye B, Williams MA, Lemma S, Deyessa N, Bahretibeb Y, Shibre T, et al. Validity of the patient health questionnaire-9 for depression screening and diagnosis in East Africa. Psychiatry Res. 2013;210(2):653-61.

23. Al-Qazaz HK, Hassali MA, Shafie AA, Sulaiman SA, Sundram S, Morisky DE. The eight-item Morisky medication adherence scale MMAS: translation and validation of the Malaysian version. Diabetes Res Clin Pract. 2010;90(2):216-21.

24. Abebe SM, Berhane Y, Worku A. Barriers to diabetes medication adherence in north West Ethiopia. SpringerPlus. 2014;3(1):195.

25. Abebe SM, Berhane Y, Worku A, Alemu S, Mesfin N. Level of sustained glycemic control and associated factors among patients with diabetes mellitus in Ethiopia: a hospital-based cross-sectional study. Diabetes, Metab Syndr Obes: Targets Ther. 2015;8:65.

26. de Oliveira-Filho AD, Morisky DE, Neves SJF, Costa FA, de Lyra DP. The 8-item Morisky medication adherence scale: validation of a Brazilian-Portuguese version in hypertensive adults. Res Social Adm Pharm. 2014;10(3):554-61.

27. Abiola T, Udofia O, Zakari M. Psychometric properties of the 3-item Oslo social support scale among clinical students of Bayero University Kano, Nigeria. Malaysian J Psychiatry. 2013;22(2):32-41.

28. Teklay G, Hussien J, Tesfaye D. Non-adherence and associated factors among type 2 diabetic patients at Jimma University specialized hospital, Southwest Ethiopia. J Med Sci. 2013;13(7):578.

29. Humeniuk R, Ali R, Babor TF, Farrell M, Formigoni ML, Jittiwutikarn J, et al. Validation of the alcohol, smoking, and substance involvement screening test (ASSIST). Addiction. 2008;103(6):1039-47.

30. Haskell WL, Lee I-M, Pate RR, Powell KE, Blair SN, Franklin BA, et al. Physica activity and public health. Updated recommendation for adults from the American College of Sports Medicine and the American Heart Association. Circulation. 2007;116(9):1081-93.

31. Morisky DE, Ang A, Krousel-Wood M, Ward HJ. Predictive validity of a medication adherence measure in an outpatient setting. J Clin Hypertens. 2008;10(5):348-54.

32. Krousel-Wood M, Islam T, Webber LS, Re R, Morisky DE, Muntner P. New medication adherence scale versus pharmacy fill rates in hypertensive seniors. Am J Manag Care. 2009;15(1):59.

33. Chung JH, Moon K, Kim DH, Min J-W, Kim TH, Hwang H-J. Suicidal ideation and suicide attempts among diabetes mellitus: the Korea National Health and nutrition examination survey (KNHANES IV, V) from 2007 to 2012. J Psychosom Res. 2014;77(6):457-61.

34. Alem A, Kebede D, Jacobsson L, Kullgren G. Suicide attempts among adults in Butajira, Ethiopia. Acta Psychiatr Scand. 1999:100:70-6.

35. Löfman S, Hakko H, Mainio A, Timonen M, Räsänen P. Characteristics of suicide among diabetes patients: a population-based study of suicide victims in northern Finland. J Psychosom Res. 2012;73(4):268-71.

36. Goodwin RD, Marusic A, Hoven CW. Suicide attempts in the United States: the role of physical illness. Soc Sci Med. 2003;56(8):1783-8.

37. Alem A, Kebede D, Jacobsson L, Kullgren G. Suicide attempts among adults in Butajira, Ethiopia. Acta Psychiatr Scand. 1999;100(S397):70-6.

38. Bitew H, Andargie G, Tadesse A, Belete A, Fekadu W, Mekonen T. Suicidal ideation, attempt, and determining factors among HIV/AIDS patients, Ethiopia. Depress Res Treat. 2016;2016:8913160.

39. Pompili $M$, Lester $D$, Innamorati $M$, De Pisa $E$, Amore $M$, Ferrara $C$, et al. Quality of life and suicide risk in patients with diabetes mellitus. Psychosomatics. 2009;50(1):16-23.

40. Pompili M, Forte A, Lester D, Erbuto D, Rovedi F, Innamorati M, et al. Suicide risk in type 1 diabetes mellitus: a systematic review. J Psychosom Res. 2014; 76(5):352-60

41. Masango S, Rataemane S, Motojesi A. Suicide and suicide risk factors: a literature review. S Afr Fam Pract. 2008:50(6):25-9.

42. Ceretta LB, Réus GZ, Abelaira HM, Jornada LK, Schwalm MT, Hoepers NJ, et al. Increased prevalence of mood disorders and suicidal ideation in type 2 diabetic patients. Acta Diabetol. 2012;49(1):227-34.

43. Lee H-Y, Hahm M-I, Lee SG. Risk of suicidal ideation in diabetes varies by diabetes regimen, diabetes duration, and $\mathrm{HbA} 1 \mathrm{c}$ level. J Psychosom Res. 2014;76(4):275-9.

44. Bot M, Pouwer F, De Jonge P, Tack C, Geelhoed-Duijvestijn P, Snoek FJ. Differential associations between depressive symptoms and glycaemic control in outpatients with diabetes. Diabet Med. 2013;30(3):e115-e22.

\section{Publisher's Note}

Springer Nature remains neutral with regard to jurisdictional claims in published maps and institutional affiliations.

\section{Ready to submit your research? Choose BMC and benefit from:}

- fast, convenient online submission

- thorough peer review by experienced researchers in your field

- rapid publication on acceptance

- support for research data, including large and complex data types

- gold Open Access which fosters wider collaboration and increased citations

- maximum visibility for your research: over $100 \mathrm{M}$ website views per year

At $\mathrm{BMC}$, research is always in progress.

Learn more biomedcentral.com/submission 